\title{
Restructuring Examination System of Institute of Engineering for Establishing Center of Excellence in Engineering Education
}

\author{
Tri Ratna Bajracharya ${ }^{1}$, Babu Ram Dawadi ${ }^{2}$, Ram Chandra Sapkota ${ }^{3}$ \\ Institute of Engineering, Tribhuvan University, Pulchowk, Lalitpur, Nepal \\ Corresponding author: ['triratna, ${ }^{2}$ baburd, ${ }^{3}$ rc.sapkota1]@ioe.edu.np
}

Received: March 28, 2017 Revised: Nov 20, $2017 \quad$ Accepted: Jan 12, 2018

\begin{abstract}
There exists different parameters that act as influencing factors to measure the quality of technical education. Nature of examination with its process and activities has direct and indirect relationship towards quality product and result status in any academic institution. Institute of Engineering (IOE) is continuously enhancing the examination process with the objective to increase the quality and pass rate in the semester examination. Being to conduct several bi-annual exams, Examination Control Division (ECD) of Institute of Engineering (IOE) is mostly the busy organization that has to manage examinations for bachelor, masters and $\mathrm{PhD}$ degree programs throughout the year. ECD conducts by-annual semester exams for regular and back exam of bachelor of engineering students having 10 streams (Civil, Computer, Electronics, Electrical, Mechanical, Geomatics, Agriculture, Industrial, Architecture and Automobile) in its four constituent campuses and ten affiliated colleges. Similarly, ECD also conducts bi-annual exams for masters of engineering programs having seven streams and 24 sub-streams. There are more than 16,000 examinees in the bachelor exam including regular and back. Additionally, successful conduction of BE/BArch/ M.Sc. entrance examinations is also an integral duty of ECD. The student pass rate in the semester exams of IOE is below expectations. This study is mostly focused on finding the factors affecting the quality results and approaches of optimizations for better education at IOE. After reviewing several factors, we proposed "restructuring of regular and back paper examinations" as one of the major approach that will help to increase the quality of education and consequently increase the pass rate in the semester examination system of IOE
\end{abstract}

Keywords: BE/BArch, admission, IOE, semester exam, quality, entrance

\section{Introduction}

Institute of engineering (IOE) is one of the decentralized institutes of Tribhuvan University and it is the biggest engineering institution in Nepal. This institute has Bachelor of Engineering, Master of Science in Engineering and Ph.D. programs. The diploma program has been phased out. This institute has more than 16,000 bachelor students, more than 900 masters' students and consequently increasing number of Ph.D. candidates. IOE has four constituent campuses located 
in eastern, central and western region of Nepal including central campus at Pulchowk, Lalitpur. The bachelor of engineering program is a four years program except architecture which has 5 years for graduation. Both the bachelor and master's programs are designed in semester system as per international standards. There are in total 10 streams in bachelor of engineering programs. Other streams in bachelor of engineering like Biomedical, Chemical and Aeronautical Engineering are under pipeline to be launched in the near future. Similarly, the institute offers masters programs in 24 different subjects in its 3 constituent campuses as specialized research courses.

It is well known that the students' entrance examination and final examination systems of the IOE has been recognized as one of the best students' evaluation system not only in Nepal but also in regional level. From the examination perspectives, number of examinations has to be run throughout the year for all streams students including entrance examination of bachelor and masters levels. The regular exam runs two times a year at the end of each semester and back paper exam runs two times a year at the mid of each semesters during winter and summer vacation. From the general calculation, examination control division of IOE has to handle more than 16,000 students (regular and back paper) in one bachelor level exam. Masters level exam runs two times a year at the end of each semester. All the examinations are to be handled by ECD of IOE. For this, ECD has to process more than 1600 packets and prepare for more than 500 question sets for one semester exam.

Like the entrance examination, the semester examination of IOE is highly prestigious. Timely conduction of semester exam and result publications are the major features of IOE Examination that helps to maintain the IOE Academic Calendar. However, the non-automated ECD activities demand for more human resources and increasing hurdles to conduct those examinations. With the increase of affiliated colleges, programs and its students, the operation challenges for the examination has been increased with the increase of failure rates, accumulation of the backpaper students to next consequents exams, shortage of physical and human resources leading to requirement of urgent review on examination patterns and system of IOE.

ECD has taken number of steps to control the quality of Education. Collecting at least three questions for a subject and moderating this into final one, scrutinizing at least $15 \%$ samples of the answer packets, evaluating the research projects and lab exam from the external examiners are the major features of IOE examination. Every subject in the semester are treated as $100 \%$ full marks in which $80 \%$ evaluation is done by ECD by taking final exam while $20 \%$ evaluation is to be performed by the course instructor who shall run number of assessment examinations as continuous assessment, seminar works, VIVA, assignment, attendance, and evaluate the individual student's performance. Similarly course/lab instructor continuously evaluate the lab activities by measuring the lab field works, reports, VIVA and internal examinations.

\section{Methodology}

It is revealed that there is a need of a kind of reform in examination system so that the IOE's aim to establish Excellency in engineering education is achieved. Therefore, a study has been conducted with the standard methodology. In this study, almost $90 \%$ admitted students as sample were taken to analyze the eligible candidates from entrance and their result in the semesters since the year 2069BS (2012AD). Similarly almost $90 \%$ samples were analyzed to identify the pattern of pass percentage in the semester exam since 2066BS (2009AD). For this analysis, a 10\% interval of secured percentage in marks were taken like greater than $90 \%, 80$ to $90 \%$, and 70 to $80 \%$ till 40 to $50 \%$. With this interval, the admitted students and their pass rates in the semester result in each 
program were analyzed. SPSS Clementine tool was used for data analysis while MS-Access \& SQL were used for cross verification and validation of data obtained for this analysis.

\section{Graduation Status of IOE}

Looking into the semester exam pass status of admitted students with different score group at their entrance exam, figure 1 shows that count of admitted students having lower score in the entrance exam is higher while their pass rate is lower in the semester exam. This indicates that the factors that affect the lower pass rate in the semester exam is the higher intake of lower scorer students in entrance exam. For the precise descriptions of the charts and figures hereafter, we introduce the following notations:

\section{TO 80: $\quad$ The range of entrance score between 70 and 80}

LT90GTEQ80: $\quad$ Score is less than $90 \%$ \& greater than or equal to $80 \%$

LT50GTEQ40: Score is less than $50 \%$ \& greater than or equal to $40 \%$

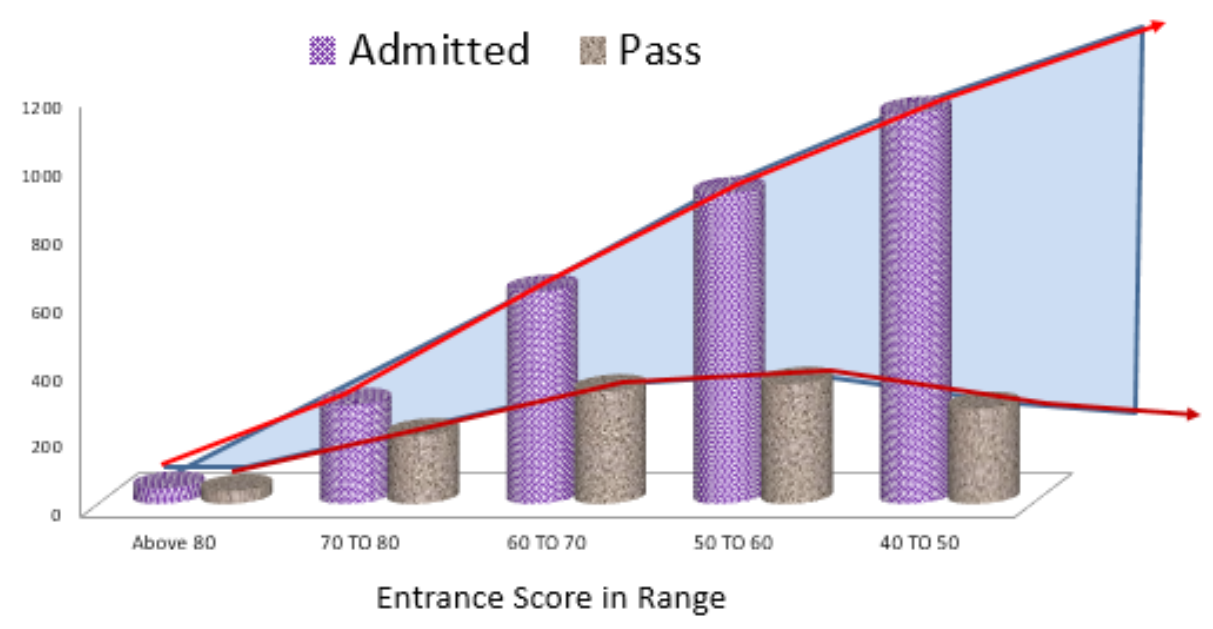

Fig. 1: Score wise admitted students and their pass status in the semester exam

Similarly looking into the semester result status since 2066(2009AD) depicted in Fig. 2, the aggregate pass percentage has been reducing in an average from $50 \%$ to $40 \%$ and then towards decreasing scenarios. This shows that on every semester, numbers of students who fail are increasing making the examination management more complex for the Examination Control Division of IOE. The causes and factors that affect the academic environment towards degrading graduation percentage of IOE have to be identified. This paper is mainly focused on the examination structure of Institute of Engineering and its impact on quality education with its implication on pass percentage of students in the semester examination system as an influencing factor of quality product. Below section focused on the cause and effects in the examination system and other factors that typically affect the academic environment at the institute for Nepalese Engineering Education system. 


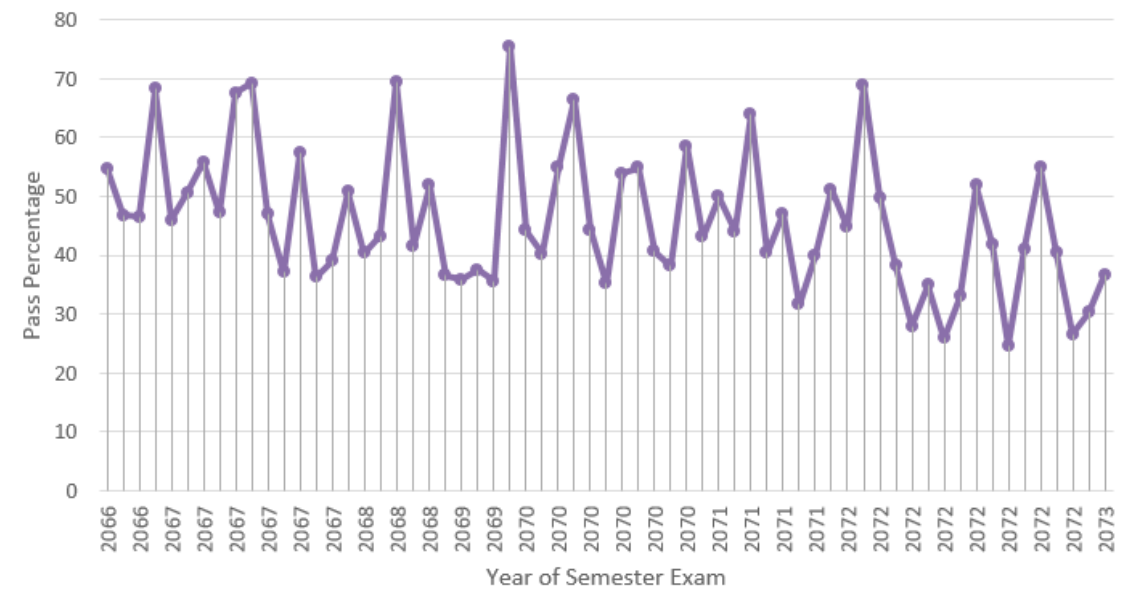

Fig. 2: Students pass percentage since 2066 (2009) in semester exam

\section{Factors that Affects and its Mitigation to Quality of Engineering Education at IOE}

Quality education has proportional relationship with different factors like institutional infrastructure and resources, research and development activities of faculty with their strength and quality, student's intake, student's family environment, evaluation scheme of the institute as well as physical and mental status of individual students.

Natrajan [6] has defined the quality of Engineering Education as: "the development of intellectual skills and knowledge that will equip graduates to contribute to society through productive and satisfying engineering careers as innovators, decision makers and leaders in the national and global economy". Similarly, Kulkarni [4] has alternatively defined that "quality in engineering education is an open system at various levels, i.e. students, teachers, curriculum, institutional and state level".

Natrajan [5] has identified the several indicators as key performance index to measure the quality of technical education. He categorized indicators with respect to three entities; student's quality, faculty quality and institutional quality. It is obvious that these three parameters shall be defined under human resources while the sufficiency of available physical resources like laboratories, library, syllabus structure, examination system, physical infrastructure like class room, building, hostels, sports etc. are additional indicators that directly and indirectly affect the quality product of engineering education in Nepal.

Pahari [5] performed observational study regarding the quality of engineering education in Nepal and identified different competency parameters that lead to increase the competency level and quality of education. The quality product in the technical education also depends on the motivation to the faculties, government investment on primary and secondary level education together with the affordability to study with respect to purchasing power of people in Nepal [3].

Every year IOE takes computer based entrance examination to select highly qualified students for bachelor and masters of engineering studies. Dawadi et al. [2] has analyzed the semester exam result status of those bachelor of engineering students and compared their score while they achieved in the entrance examination. This clearly shows that the higher ranked students in the entrance have greater pass ratio in their semester exam. However, the pass percentage is deteriorating day by day leading to serious situation that number of back paper applicants are recursively increasing. 
Looking into last three years intake, out of almost 11, 000 applicants in the entrance examination, IOE admits only about $30 \%$ meritorious students graduate and among them about $40 \%$ graduates as a regular examinee every year. The remaining $60 \%$ students go for back exams and the number as a consequence accumulates. Hence, the back examiners are increasing. Following sections briefly discusses the causes, effects and factors affecting the pass rate of IOE semester results.

\subsection{Semester Exam Structure of IOE}

IOE has a fix Academic Calendar that specifies the start of and end of course as well as conducts the exam according to the calendar date. Two semesters in a year are divided as November to April Session and May to September session. Fig. 3 shows that the back paper exam of previous semester held tentatively at the mid of next semester. That means generally 3 months after the regular exam, the back paper exam happens.

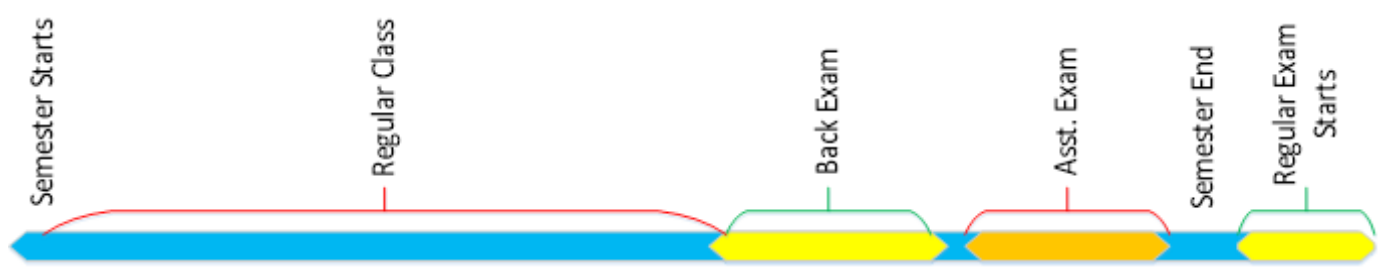

Fig. 3: Existing Semester and Exam Structure of IOE

With the increasing number of back-paper students, the majority of students in the regular semester classes are back-paper holders. Whenever the semester starts, students simply plan for the preparation of back paper exam hampering the regular classes. In some affiliated colleges, students bunk the regular class almost one month before the back exam starts. However the regular class duration is 90 days as per IOE calendar, the teacher student contact hours is very less due to back paper exam set at the mid of regular semester. Even after completing the back exam, students enter into the assessment examination as a regular process which also disturb the regular classes. Due to this situation, it seems as if student won't be mentally prepared for the regular class and teacher-student's contact hour is not sufficient, however the calendar mentions the sufficient days according to university rule. These kinds of disturbances at the mid of the semester is impacting the regular exam leading to increase of failure rate. The concept of back exam in the middle of semester was introduced since 2009 with the objective that student's pass rate shall be increased if IOE can take back exam as early as possible after completing regular exam because it is expected that students with fresh mind shall be able to pass the exam. But Fig. 2 depicts the current scenarios where the objective is not achieved. If IOE is able to conduct such kind of back exam immediately after completing regular exam before the regular class starts, the objective shall be achieved but unfortunately the ECD could not conduct the back exam of previous semester immediately after completion of its regular exam. Hence restructuring the exam system is expected to reduce the fail rate in the regular semester. Practically, the back exam is hampering the regular classes and lab activities. Reforming the semester exam as per depicted in Fig. 4, i.e. If the back exam slot is moved behind the regular exam, the disturbances in the regular exam will be minimized with the sufficiency of teacher-student contact hours and the students would fully focused on the regular exam which shall be helpful to increase the pass percentage. After completing the regular exam, only the back paper students will remain focus in their back exam while the regularly passed students shall enjoy their free time planning for next semester classes. 


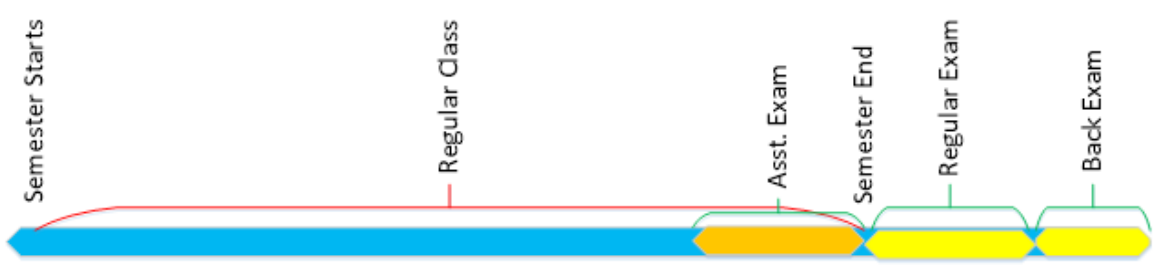

Fig. 4: Reformed Semester and Exam Structure of IOE

\subsection{Strategy for Quality Intake during the Admission}

Looking into the admission status of year 2016AD (2073BS), the admitted quantity below the score 50 is comparatively high while figure 1 already relates the status of low score students in their semester result. The important thing is that the students in the entrance score range 50 to 60 are higher in value who are missed in the admission. If IOE catch those higher rank students, admission count of lower rank (below 50) students shall be minimized. Moreover, this would help to increase the pass percentage in the semester exam.

Looking into the table of figure 5, objectively IOE should nullify the admission of the students having score below 50. But the total admission seats of IOE is 3712 which is not fulfilled by the students having score above 50 even if IOE considered the missed students. This indicates that IOE has to attract more applicants in the entrance exam so that higher scorer shall be increased for the quality intake in the admission. Government should follow one window system providing equal opportunities [1] to all students who are interested towards engineering education in Nepal. Hence, an appropriate engineering education policy has to be formulated that helps to reduce brain drain and attract students to study engineering education within the nation.

\begin{tabular}{|l|c|c|c|}
\hline Score Range & Admitted & Eligible & Missed \\
\hline GTEQ80 & 65 & 66 & 1 \\
\hline LT80GTEQ70 & 279 & 295 & 16 \\
\hline LT70GTEQ60 & 545 & 634 & 89 \\
\hline LT60GTEQ50 & 904 & 1490 & 586 \\
\hline LT50 & 1241 & 3689 & 2448 \\
\hline Total & 3034 & 6174 & 3140 \\
\hline
\end{tabular}

Admitted
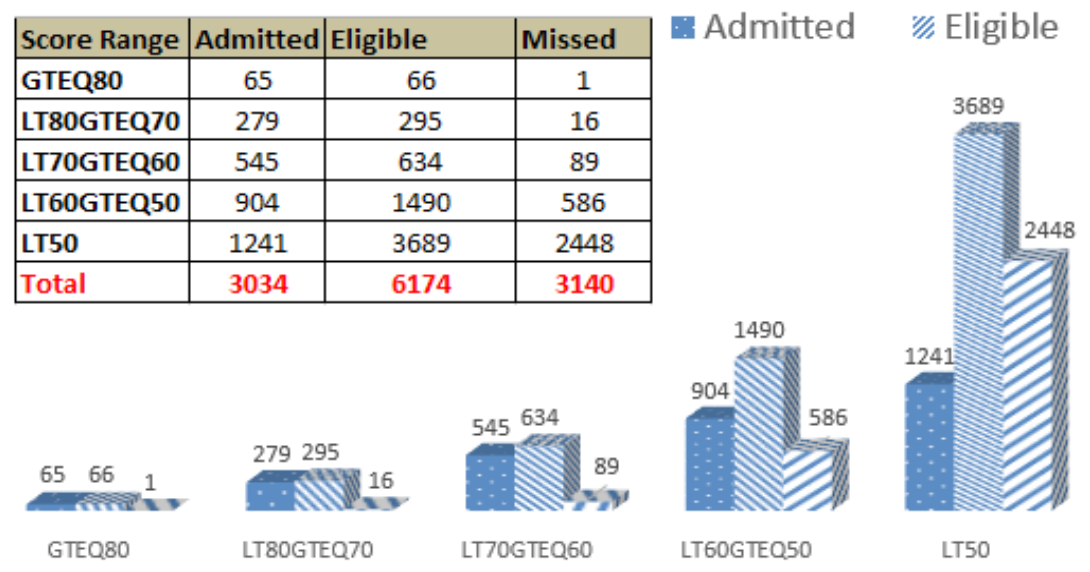

Fig. 5: Entrance and Admission status of IOE students in the year 2073BS (2016AD)

\subsection{Academic Environment and Facilities of IOE Constituent Campus \& Affiliated Colleges}

Among four constituent campuses and ten affiliated colleges; Pulchowk Campus is the first ranked institute with respect to physical facilities, qualified faculties, and student's quality while other constituent campuses are considerably better due to the government investment in its development. The limited physical resources, limited faculties (fresh graduates as a faculty) and profit oriented activities are the major factors that affect the quality education that are to be well addressed by IOE itself in some of its affiliated colleges. 


\subsection{Syllabus Structure and Teaching/Learning Process at IOE}

Due to the rapid change in teaching/learning paradigm world-wide with the proper use of ICT in the learning process, the world's education system is highly modernized while IOE is supposed to be still following the traditional teaching/learning activities. The existing syllabus structure and subjects has to be revised into the suitable one that must adapt with the modern day education requirement. Uniformity in the pattern of syllabus content and structure, automation in the examination activities, proper training and regular workshop for the faculty and staffs, suitable performance appraisal system for faculty and staffs, research oriented class room learning environment, timely review of the syllabus, continuous regulation/monitoring of the academic environment etc. are also needed to be considered for the proper and standard quality education as a consequence, the pass percentage and the quality graduates shall be increased at IOE.

\section{Conclusion}

It is basically review of the key performance index of maintaining quality in the engineering education and analyzing the major factors that affect the pass percentage in the semester result of IOE. Besides several factors, it is expected that restructuring of the semester exams, automation in examination activities, uniformity in syllabus pattern and improvement in teaching/learning paradigm are the major factors that improve the quality in the engineering education and increase the pass percentage in semester exam result of IOE. Looking into the past and current activities, IOE is continuously improving its academic environment by establishing Excellency in its BE/BArch \& M.Sc. Entrance examination as well as admission system, proceeding towards automation in the semester exam and web based resource management, revision of syllabus structure, increasing the establishment of research centers, encouraging the faculties towards research are some of the additional activities of IOE that are aimed at improving the quality and achieve the standards of world class education in Nepal.

Acknowledgement: This research was supported by Institute of Engineering, Dean's Office under the mission "Reform of Institute of Engineering" with its regular grants on "Steps towards Excellent Academic Environment at IOE".

\section{References}

[1] Dawadi BR (2016), नेपालमा ईन्जिनियिरड़ शिक्षाको गुणस्तर अवस्था र इ.अ.सं. को भूमिका, [online] Available: https://www.researchgate.net/profile/Babu_Dawadi/contributions

[2] Dawadi BR and Baral DS (2017), Towards Automation in the Admission Process as a Tool to Enhance Quality of Engineering Education at Tribhuvan University, Journal of Institute of Engineering, 13(1), Article in the press.

[3] Joshi RR and Joshi M (2015), Quality Assurance in Engineering in Nepal: Issues and Challenges, $7^{\text {th }}$ International Forum on Engineering Education (IFEE2015)", University of Sharjah, UAE.

[4] Kulkarni P (1999), Quality in Engineering Education, Journal of Engineering Education, 1025.

[5] Pahari BR (2009), Competency Level of Engineering Graduates and Quality of Engineering Education of Nepal, Journal of the Institute of Engineering, 7(1) :1-11.

[6] Natrajan R (2000), The Role of Accreditation in promoting Quality Assurance of Technical education, International Journal of Engineering Education, 16(2) : 85-96. 